\title{
Atypical Kawasaki Disease in a 4 Years Old Child with Mumps
}

\author{
Prakash Banjade, ${ }^{1}$ Kiran Subedi ${ }^{1}$ \\ 'Department of Pediatrics, Kathmandu Medical College Teaching Hospital, Kathmandu, Nepal.
}

\section{ABSTRACT}

Kawasaki disease is an acute febrile condition seen in children. However, it is also well recognized that some patients do not fulfill the classic diagnostic criteria for the diagnosis of Kawasaki disease. The incomplete form of Kawasaki disease is termed as 'Incomplete KD' or 'Atypical KD'. This is a case of 4 years old child with fever and mumps. He had bilateral cervical adenitis. Patient failed to respond to IV antibiotics fulfilled the criteria of incomplete Kawasaki disease. The child was managed with high dose aspirin until the child was afebrile for 48 hours. Kawasaki disease is a common vasculitis in children. Atypical cases might be missed if there is concomitant viral illness. Hence the identification and management of Kawasaki disease is paramount to decrease the mortality related to the cardiac disease.

Keywords: bilateral cervical adenitis; fever and mumps; failed to respond IV antibiotics; incomplete kawasaki disease.

\section{INTRODUCTION}

Kawasaki disease is acute, self-limited systemic type of vasculitis that occurs predominantly in young children. After first case reported by Tomisaku Kawasaki in Japan, ${ }^{1}$ it is recognized as the leading cause of acquired heart disease in children in developed countries. However, pediatricians sometimes encounter febrile children who do not fulfill the diagnostic criteria but have several findings compatible with those of Kawasaki disease. In this situation, the diagnosis of incomplete Kawasaki disease is a clinical challenge. It cannot be avoided by delaying the diagnosis because of the risk of coronary complications pertaining even to the incomplete presentation of the disease..$^{2,3}$

The reported prevalence of incomplete presentation was 15 to $36.2 \%$ among patients with Kawasaki disease. ${ }^{4,5}$ Children with incomplete presentation were more likely to be at the extremes of the age spectrum as compared to those with complete presentation. The prevalence of incomplete presentation was relatively higher inthe younger-aged patients. ${ }^{4,5}$

\section{CASE REPORT}

A 4 years old male child presented to hospital with swelling behind left ear and fever for 7 days. The child had been without any symptoms 7 days back. He started to have fever (maximum recorded temperature of $103^{\circ} \mathrm{F}$ with no chills or rigors). He had swelling behind the left ear, painful (mild in intensity and relieved with analgesic medications) and difficulty in moving the neck forward and side to side. Swelling was pea sized and multiple in numbers including the neck bilaterally. Size of the swelling remained constant throughout. No history of history of right ear pain, ear discharge, redness of eyes, eye discharge, abnormal body movements, LOC, difficulty in swallowing, runny nose, cough, chest pain, fast breathing. He didn't have h/o pain while chewing, loose stool, nausea, vomiting, abdominal pain, increase frequency of urination, burning urination, blood in urine.

Correspondence: Dr. Prakash Banjade, Department of pediatrics, Kathmandu Medical College Teaching Hospital, Kathmandu, Nepal. Email: ur.prakash25@gmail.com, Phone: +977-9851222849. 
He had history of contact with friends having mumps. No history of joint swelling or rashes. He has cats at home sometimes plays with them but no history of scratch by them and no history of tick bite, and history of swelling below the ears as described by mother as mumps in the right side had subsided at the time of presentation. He had no history of dental caries no facial lesions, history of swelling of the right lower limbs ankle subsiding on its own.

He was treated with Azithromycin for 5 days with Cefixime 2 days already, when the child presented to hospital.

On Examination, child was alert and looked in no apparent distress but looked toxic.

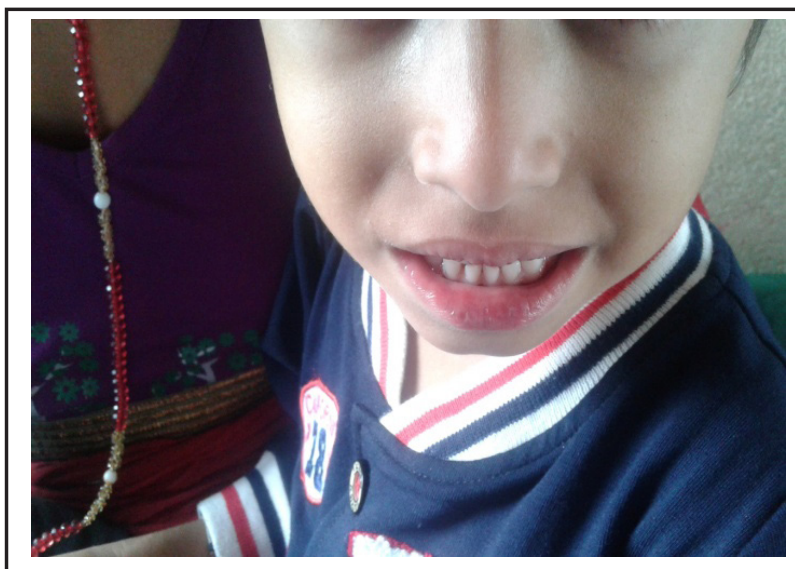

Figure 1. Mucosal changes and lip cracking.

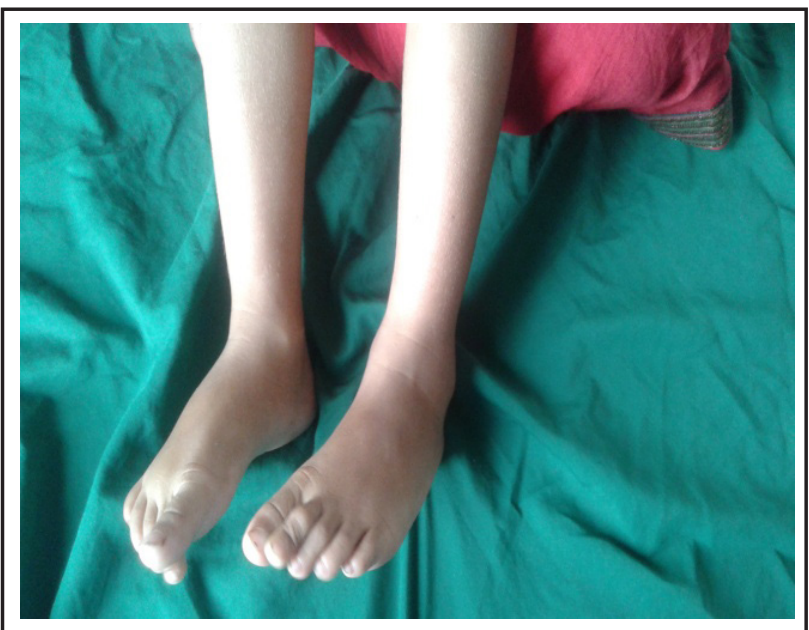

Figure 2. Edema of the feet, right ankle.

Temperature was $102^{\circ} \mathrm{F}$, axillary pulse rate was 110 / min with normal character, volume with no radioradial and radio-femoral delay. All peripheral pulses were palpable. Respiratory rate was 32 per minutes, $\mathrm{SpO} 2-94 \%$ in right arm. BP was 100/60 mm Hg right arm supine. Pallor, icterus, cyanosis were absent. Edema and lymphadenopathy were present. Multiple, discrete, tender, sized less than $1 \mathrm{~cm}$ in pre-auricular, post auricular, submandibular and inguinal area were palpable. Axillary lymph nodes were not palpable.

On examination of head, there was no scalp lesion, hair was normal. Examination of eye revealed no redness and discharge. Ear examination revealed bilateral wax. Oral cavity examination showed no ulcers, normal pharynx, stenson's duct, no dental caries. Face examination reveal no rashes no lesions.

Investigations (on $7^{\text {th }}$ day of symptom) showed hemoglobin $10.8 \mathrm{gm} / \mathrm{dl}$, total count 18,000/. $\mathrm{mm}^{3}$ (neutrophils 65\%, lymphocytes 35\%), platelets$50,000 / \mathrm{mm}^{3}$, CRP present. Chest X-ray was normal. Urine microscopic examination were normal, viral panel EBV, mumps, adenovirus were sent in which mumps $\lg \mathrm{M}$ was positive.

During the hospital stay till 3 days of treatment with IV antibiotics which was started in view of severe bacterial infection, the child remains febrile with temperature up to $103^{\circ} \mathrm{F}$, so blood investigations were sent on $4^{\text {th }}$ day of hospital admissions and $11^{\text {th }}$ day of illness.

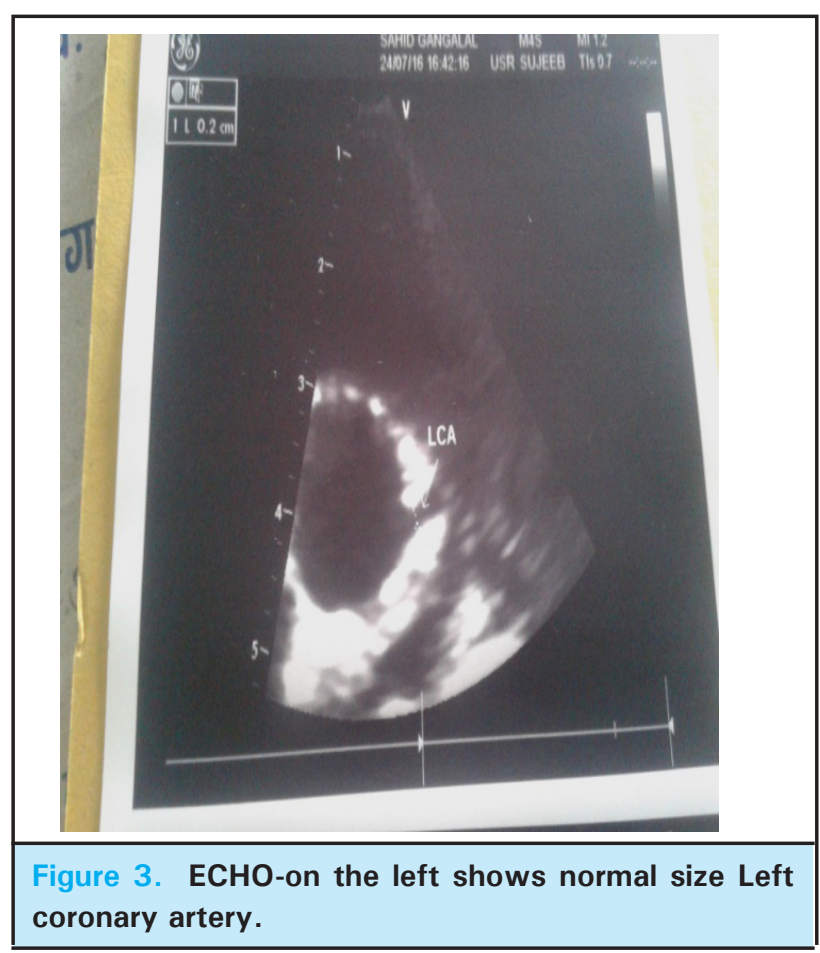




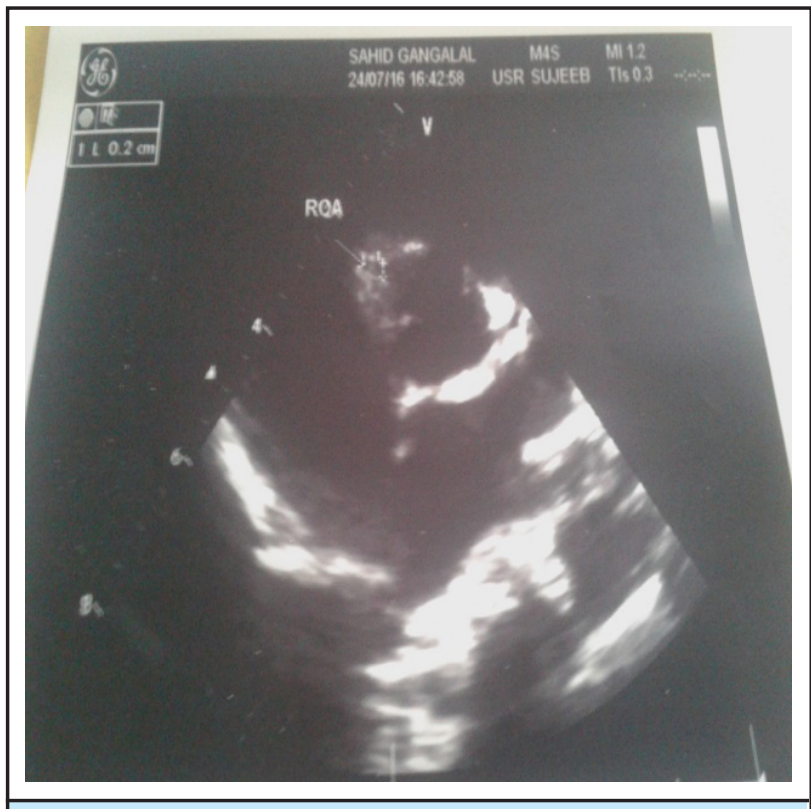

Figure 4. Normal size Right coronary artery in ECHO.

His baseline laboratory work-up were sent. Abnormal laboratory findings included a low hemoglobin (10.4 $\mathrm{gm} / \mathrm{dl})$, a low hematocrit, raised white cell count (21 $\times 109 / \mathrm{L})$, with dominance of neutrophils (85\%), and thrombocytosis (platelet count of $539 \times 10^{3} / \mathrm{mm}^{3}$ ). The rest of the work-up including electrolyte and renal function workup was within the normal range. Hence a diagnosis of incomplete Kawasaki disease was made since few of the clinical features were met according to Japanese criteria ${ }^{6}$ along with the laboratory criteria's.

Table 1. Japanese criteria for diagnosis of Kawasaki disease.

Fever persisting $\geq 5$ days

Bilateral conjunctival congestion

Changes of lips and oral cavity

Polymorphous exanthema

Changes of peripheral extremities

Acute non-purulent cervical lymphadenopathy

\section{DISCUSSION}

Kawasaki disease is an acute febrile condition seen in children. Even though it was first reported in Japan about 30 years ago, the original diagnostic criteria defined by Dr. Tomisaku Kawasaki in 1967 are still authentic and widely used today. However, it is also well recognized that some patients do not fulfill the classic diagnostic criteria for the diagnosis of KD. The incomplete form of KD is termed as Incomplete KD' or 'Atypical KD'. Because incomplete KD is not a mild form of KD, children remain at similar risk for cardiovascular sequelae as that of complete KD. ${ }^{7}$ Since the disease has a similar risk of coronary artery abnormalities(CAA) as complete $K D,{ }^{8-10}$ it is necessary to make an accurate diagnosis in order to prevent the development of coronary artery abnormalities CAA.

Table 2. Additional laboratory criteria and Echocardiography criteria according to Japanese criteria. ${ }^{11}$

(A)

Serum albumin $\geq 3.0 \mathrm{~g} / \mathrm{dl}$

Anemia for age

Elevation of alanine aminotransferase

Platetelets after 7 days $\geq 450,000 / \mathrm{mm}^{3}$

WBC $\geq 15,000 / \mathrm{mm}^{3}$

Urine $\mathrm{WBC} \geq 10 / \mathrm{HPF}$

(B)

$Z$ score of $L A D$ or $R C A \geq 2.5$

Coronary arteries meet japanese Ministry of Health

Criteria for aneurysm

Internal Lumen diameter

$>3 \mathrm{~mm}$ in children $<5$ years old, or

$>4 \mathrm{~mm}$ in children $>5$ years old

Of a segment measures $\geq 1.5$ times that of an adjacent segment

Clearly irregular coronary lumen

Other 6 suggestive features (if $\geq 3$ features, positive)

Perivascular brightness of coronary arteries

Lack of tapering of coronary arteries

Decreased LV function

Mitral regurgitation

Pericardial effusion

$Z$ score in LAD or RCA of 2 to 2.5

According to the algorithm of the guidelines, assessment using laboratory tests was required and fulfilled $\geq 3$ supplemental laboratory criteria (anemia for age, platelets after 7 days $\geq 45 \times 10^{\wedge} 4 / \mu \mathrm{L}, \mathrm{WBC}$ counts $\geq 15000 / \mu \mathrm{L}$ and alanine aminotransferase. Therefore, we considered this patient to be suffering from incomplete Kawasaki disease was started on high dose aspirin however was not started on IV Ig because studies have shown little benefit after 10 days in preventing coronary complications and risk to benefit ratio was high. Presented case is of atypical Kawasaki disease causing dilemma to the physicians in reaching the diagnosis because of the overlapping presentations. Physicians need to recognize that overlapping viral illness can lead to the delay in diagnosis of grave 
conditions like incomplete Kawasaki disease, despite the use of established guidelines.

Conflict of Interest: None.
Consent: JNMA Case Report Consent Form was signed by the patient and the original is attached with the patient chart.

\section{REFERENCES}

1. Kawasaki T. Acute febrile mucocutaneous syndrome with lymphoid involvementwith specific desquamation of the fingers and toes in children. Arerugi. 1967 Mar;16:178-222. [PubMed]

2. Sonobe T, Kiyosawa N, Tsuchiya K, Aso S, Imada Y, Imai Y, et al. Prevalence of coronary artery abnormality in incomplete Kawasaki disease. Pediatr Int. 2007;49(4):421-6. [PubMed]

3. Witt MT, Minich LL, Bohnsack JF, Young PC. Kawasaki disease: more patients are being diagnosed who do not meet American Heart Association criteria. Pediatrics. 1999;104:e10. [Full Text]

4. Chang FY, Hwang B, Chen SJ, Lee PC, Meng CC, Lu JH. Characteristics of Kawasaki disease in infants younger than six months of age. Pediatr Infect Dis J. 2006;25:241-4. [ㅍull Text]

5. Chuang $\mathrm{CH}$, Hsiao $\mathrm{MH}$, Chiu $\mathrm{CH}$, Huang $\mathrm{YC}$, Lin $\mathrm{TY}$. Kawasaki disease in infants three months of age or younger. J Microbiol Immunol Infect. 2006;39(5):387-91. [PubMed]

6. Kawasakidisease.org [Internet]. Kawasakidisease.org. 2016 [cited 9 October 2016]. [Full Text]
7. Royle JA, Williams K, Elliott E, Sholler G, Nolan T, Allen R, Isaacs D. Kawasaki disease in Australia, 1993-1995. Arch Dis Child. 1998;78:33-9. [․ull Text]

8. Rowley AH, Gonzalez-Crussi F, Gidding SS, Duffy CE, Shulman ST. Atypical Kawasaki Disease with Coronary Artery Involvement. J Pediatr. 1987;110:409-13. [Full Text]

9. Witt MT, Minich LL, Bohnsack JF, Young PC. Kawasaki disease: more patients are being diagnosed who do not meet American Heart Association criteria. American Academy of Pediatrics. 1999;104:e10. [Full Text]

10. Stapp J, Marshall GS. Fulfillment of diagnostic criteria inkawasaki disease. Southern Medical Journal. 2000;93(1):44-7. [Full Text]

11. Newburger JW, Takahashi M, Gerber MA, Gewitz MH, Tani LY, Burns JC, et al. Diagnosis, treatment, and long-term management of Kawasaki disease: a statement for health professionals from the Committee on Rheumatic Fever, Endocarditis, and Kawasaki Disease, Council on Cardiovascular Disease in the Young, American Heart Association, American Academy of Pediatrics. Circulation. 2004;110(17):2747-71. [PubMed]

This work is licensed under a Creative Commons Attribution 4.0 International License. The images or other third party material in this article are included in the article's Creative Commons license, unless indicated otherwise in the credit line; if the material is not included under the Creative Commons license, users will need to obtain permission from the license holder to reproduce the material. To view a copy of this license, visit http://creativecommons.org/licenses/by/4.0/ 